\title{
$\angle S$ Research Square \\ Use of telemedicine for follow-up of lupus nephritis in the COVID-19 outbreak: the 6-month results of a randomized controlled trial
}

Ho so

The Chinese University of Hong Kong https://orcid.org/0000-0001-7113-9390

\section{Evelyn CHOW}

The Chinese University of Hong Kong

Isaac T CHENG

The Chinese University of Hong Kong

Sze-Lok LAU

The Chinese University of Hong Kong

Tena K LI

The Chinese University of Hong Kong

\section{Cheuk-Chun SZETO}

The Chinese University of Hong Kong

\section{Lai Shan TAM ( $\nabla$ lstam@cuhk.edu.hk)}

The Chinese University of Hong Kong

\section{Research Article}

Keywords: systemic lupus erythematosus, lupus nephritis, telemedicine, telehealth

Posted Date: April 26th, 2021

DOl: https://doi.org/10.21203/rs.3.rs-463449/v1

License: (9) (i) This work is licensed under a Creative Commons Attribution 4.0 International License. Read Full License

Version of Record: A version of this preprint was published at Lupus on March 7th, 2022. See the published version at https://doi.org/10.1177/09612033221084515. 


\section{Abstract}

Objective To evaluate the short-term patient satisfaction, compliance, disease control and infection risk of telemedicine (TM) compared with standard in-person follow-up (FU) for patients with lupus nephritis (LN) during COVID-19.

Methods This was a single-center open-label randomized controlled study. Consecutive patients followed at the LN clinic were randomized to either TM or standard FU (SF) group in a 1:1 ratio. Patients in the TM group received FU via videoconferencing. SF group patients continued conventional in-person outpatient care. The 6-month data were compared and presented.

Results From June to December 2020, 122 patients were randomized (TM: 60, SF: 62) and had at least 2 FUs. There were no baseline differences, including SLEDAI-2k and proportion of patients in lupus low disease activity state (LLDAS), between the 2 groups except a higher physician global assessment score (PGA) in the TM group. After a mean FU of $19.8 \pm 4.5$ weeks, the overall patient satisfaction score was higher in the TM group. More patients in the TM group had hospitalization (15/60, 25.0\% vs 7/62, 11.3\%; $p=0.049)$ with higher baseline PGA $(O R=1.15,95 \% \mathrm{Cl} 1.07-1.23)$ being the independent predictor. The proportions of patients remained in LLDAS were similar in the 2 groups (TM: $75.0 \%$ vs SF: $74.2 \%, p=$ 0.919). None of the patients had COVID-19.

Conclusion TM FU resulted in better patient satisfaction and similar short-term disease control in patients with LN compared to standard care. However, it was associated with more hospitalizations and might need to be complemented by in-person visits especially in patients with higher PGA.

\section{Significance And Innovations}

- In lupus nephritis patients, telemedicine follow-up resulted in better overall patient satisfaction compared with standard in-person care.

- The short-term disease control was similar in patients received telemedicine and standard care.

- However, more patients followed up by telemedicine required hospitalization.

- A hybrid mode of follow-up incorporating telemedicine and in-person visits when necessary might be optimal.

\section{Introduction}

Systemic lupus erythematosus (SLE) is a chronic remitting-relapsing disease that affects multiple organ systems. Patients with SLE are at increased risk of severe COVID-19 due to the underlying disease, comorbidities and use of immunosuppressants (IS) $(1,2)$. During this unusual period, vulnerable patients such as those with lupus nephritis faced the difficult choice between risking severe acute respiratory syndrome coronavirus 2 (SARS-CoV-2) exposure during a clinic visit and postponing the needed care. An alternative option would be to adopt telemedicine (TM) or telehealth, the use of telecommunication 
technologies to provide medical information and services, to maintain medical care while minimizing infection exposure. Indeed, the use of TM has been recommended by international rheumatology societies after the outbreak $(3,4)$.

Despite being widely advocated during this pandemic, the evidence supporting the use of TM compared to usual in-person FU in rheumatology has been limited. According to a systematic review in 2017, there is no good evidence in supporting the use of TM for managing rheumatic diseases (5). In a subsequent randomized controlled trial, it was concluded that a TM FU could achieve similar disease control as conventional care in rheumatoid arthritis patients with low disease activity or remission (6). Two studies conducted during the initial phase of COVID-19 reported moderate acceptance of TM as the mode of care in patients with connective tissue diseases $(7,8)$. However, there is no data on the clinical outcome of TM FU in patients with lupus nephritis. We hypothesize that TM is a feasible and safe mode of health-care delivery while maintaining disease control in these patients.

We conducted a randomized controlled trial comparing TM and standard in-person care for the follow-up of patients with lupus nephritis. In view of the need for timely evidence on this novel mode of care, we reported in this article the 6-month results of the study focusing on patient satisfaction, compliance, disease control and infection risk during the COVID-19 outbreak.

\section{Patients And Methods}

\section{Study design and patients}

This was a single-center open-label randomized controlled trial of a 12-month duration. The study was conducted at a regional hospital in Hong Kong. From May 2020, consecutive adult patients with a diagnosis of SLE according to the 2019 EULAR/ACR classification criteria followed up at the lupus nephritis clinic were invited to participate in the study if they were willing to come back for routine blood and urine tests (9). Patients (or carers) needed to possess the technology for conducting a TM visit. Patients were excluded if they were pregnant or incapable of answering a questionnaire. Participants were randomized in a ratio of 1:1 to either TM (TM group) or standard FU (SF group) using a computergenerated random number sequence. They were asked to fill in an online questionnaire post-consultation regarding their satisfaction of the various aspects of the FU (supplementary Fig. 1). The responses were assigned a value of 0 to 4 (strongly disagree to strongly agree), with a higher score indicating that the respondent was satisfied with the FU and a 2 indicating a neutral response.

\section{Interventions and assessments}

Patients randomized to receive TM FU were scheduled for a video teleconference consultation. An inperson clinic consultation could be arranged as required by the patients or clinicians. Patients in the SF group received standard in-person outpatient care. Similarly, a TM consultation could be arranged as 
required. The frequency of visits was based on clinical judgements, as well as joint decisions of the attending rheumatologists and patients in both groups.

Disease related variables recorded at baseline included: disease duration, comorbidities, LN class, 24hour urine protein, IS use, SLE disease activity and Systemic Lupus International Collaborating Clinics/American College of Rheumatology (SLICC/ACR) Damage Index (SDI) (10). Prior to each consultation the patients needed to have blood (complete blood picture, liver and renal function tests, complement components [C3 and C4] and anti-dsDNA) and 24-hr urine total protein checked.

Standardization and calibration of laboratory tests were performed regularly. SLE disease activity at each consultation was assessed by the Systemic Lupus Erythematosus Disease Activity Index 2000 (SLEDAl$2 \mathrm{k}$ ) and physician global assessment (PGA) (11). Disease flares were captured with the SELENA flare index.

Recently, remission and lupus low disease activity state (LLDAS) were agreed to be the meaningful targets for managing lupus patients in order to prevent damage accrual and improve quality of life (12). SLE disease remission was defined as absence of clinical activity with no use of systemic glucocorticoids and IS. LLDAS was defined as a SLEDAI $2 \mathrm{k} \leq 4$, PGA $\leq 1$ with $\mathrm{GC} \leq 7.5 \mathrm{mg}$ of prednisone and well tolerated IS agents (12). In both groups, medication titration was based on a shared decision between the patient and the treating clinician aiming at achieving remission or LLDAS. All FUs were performed by rheumatologists or nephrologists with more than 3 years of experience in managing patients with lupus nephritis. Prescribed medications could be collected in-person by the patients or their designated representatives at the hospital or community pharmacies with standard charges which could be settled electronically.

\section{Statistical analysis}

The patients in the TM and SF groups were compared by chi-squared test or Fisher's exact test and Student's t-test or Mann-Whitney $U$ test where appropriate at baseline and at the latest FU. Differences in the changes from baseline to the latest FU within-group (e.g disease activity parameters) were analyzed by Wilcoxon test, and between-group changes by Mann-Whitney $\mathrm{U}$ test. Multivariate regression models were used to adjust for the baseline differences between the two groups if any. A 2-tailed probability value of $p<0.05$ was considered statistically significant. Statistical analyses were performed using the Statistics Package for Social Sciences (IBM SPSS V.26.0, IBM Corporation, Armonk, NY, USA). 
Table 1

Baseline clinical data of the recruited patients and comparison between the telemedicine/standard follow-up groups

\begin{tabular}{|c|c|c|c|c|}
\hline & $\begin{array}{l}\text { Overall } \\
(n= \\
122)\end{array}$ & $\begin{array}{l}\text { Telemedicine } \\
\text { group }(n=60)\end{array}$ & $\begin{array}{l}\text { Standard follow- } \\
\text { up group }(n=62)\end{array}$ & P-value \\
\hline Age in years & $\begin{array}{l}44.4 \pm \\
11.5\end{array}$ & $44.1 \pm 11.7$ & $44.7 \pm 11.5$ & 0.779 \\
\hline Gender: Female & $\begin{array}{l}111 \\
(91.0)\end{array}$ & 55 (91.7) & $56(90.3)$ & 0.796 \\
\hline $\begin{array}{l}\text { Disease duration in } \\
\text { years }\end{array}$ & $\begin{array}{l}15.1 \pm \\
9.0\end{array}$ & $16.2 \pm 8.7$ & $14.0 \pm 9.1$ & 0.115 \\
\hline $\begin{array}{l}\text { Nephritis class III, IV } \\
\text { or V }\end{array}$ & $\begin{array}{l}108 \\
(88.5)\end{array}$ & $54(90.0)$ & $54(87.1)$ & 0.427 \\
\hline $\begin{array}{l}24 \text { hour urine } \\
\text { proteinuria in gram }\end{array}$ & $\begin{array}{l}0.51 \pm \\
0.63\end{array}$ & $0.53 \pm 0.60$ & $0.50 \pm 0.65$ & 0.712 \\
\hline $\begin{array}{l}\text { Current use of } \\
\text { prednisolone }\end{array}$ & $\begin{array}{l}112 \\
(91.8)\end{array}$ & $57(95.0)$ & 55 (88.7) & 0.323 \\
\hline $\begin{array}{l}\text { Daily prednisolone } \\
\text { dose in } \mathrm{mg}\end{array}$ & $\begin{array}{l}5.51 \pm \\
4.21\end{array}$ & $5.69 \pm 4.17$ & $5.34 \pm 4.29$ & 0.570 \\
\hline $\begin{array}{l}\text { Use of } \\
\text { immunosuppressant }\end{array}$ & $\begin{array}{l}90 \\
(73.8)\end{array}$ & $46(76.7)$ & $44(71.0)$ & 0.474 \\
\hline SLEDAI-2K & $\begin{array}{l}3.65 \pm \\
2.33\end{array}$ & $4.00 \pm 2.34$ & $3.30 \pm 2.29$ & 0.097 \\
\hline PGA & $\begin{array}{l}0.56 \pm \\
0.65\end{array}$ & $0.67 \pm 0.69$ & $0.45 \pm 0.60$ & 0.003 \\
\hline LLDAS & $\begin{array}{l}78 \\
(63.9)\end{array}$ & $36(60.0)$ & $42(67.7)$ & 0.251 \\
\hline Remission & $0(0)$ & $0(0)$ & $0(0)$ & $\mathrm{n} / \mathrm{a}$ \\
\hline $\begin{array}{l}\text { Presence of } \\
\text { comorbidity }\end{array}$ & $\begin{array}{l}87 \\
(71.3)\end{array}$ & $40(66.7)$ & $47(75.8)$ & 0.264 \\
\hline $\begin{array}{l}\text { Number of } \\
\text { comorbidity }\end{array}$ & $\begin{array}{l}1.34 \pm \\
1.33\end{array}$ & $1.45 \pm 1.53$ & $1.24 \pm 1.11$ & 0.866 \\
\hline SDI & $\begin{array}{l}0.93 \pm \\
1.15\end{array}$ & $1.08 \pm 1.28$ & $0.78 \pm 0.98$ & 0.243 \\
\hline
\end{tabular}

Data are reported as mean \pm SD or number (\%). SLEDAI-2k: Systemic Lupus Erythematosus Disease Activity Index 2000; PGA: physician global assessment; LLDAS: lupus low disease activity state; SDI: Systemic Lupus International Collaborating Clinics/American College of Rheumatology (SLICC/ACR) Damage Index; HAQ-DI: Health Assessment Questionnaire Disability Index; and HADS: Hospital Anxiety and Depression Scale. 


\begin{tabular}{|c|c|c|c|c|}
\hline & $\begin{array}{l}\text { Overall } \\
(n= \\
122)\end{array}$ & $\begin{array}{l}\text { Telemedicine } \\
\text { group }(n=60)\end{array}$ & $\begin{array}{l}\text { Standard follow- } \\
\text { up group }(n=62)\end{array}$ & P-value \\
\hline HAQ-DI & $\begin{array}{l}0.23 \pm \\
0.46\end{array}$ & $0.25 \pm 0.47$ & $0.21 \pm 0.44$ & 0.571 \\
\hline \multirow{2}{*}{$\begin{array}{l}\text { HADS: } \\
\text { Anxiety scale } \\
\text { Depression scale }\end{array}$} & $6.07 \pm$ & \multirow{2}{*}{$\begin{array}{l}6.20 \pm 4.19 \\
5.73 \pm 3.93\end{array}$} & \multirow{2}{*}{$\begin{array}{l}5.93 \pm 4.09 \\
5.70 \pm 4.68\end{array}$} & \multirow{2}{*}{$\begin{array}{l}0.720 \\
0.724\end{array}$} \\
\hline & $\begin{array}{l}5.72 \pm \\
4.31\end{array}$ & & & \\
\hline \multirow{2}{*}{$\begin{array}{l}\text { LupusQoL score for: } \\
\text { Physical health }\end{array}$} & \multirow{2}{*}{$\begin{array}{l}79.1 \pm \\
20.3\end{array}$} & $78.2 \pm 20.3$ & $80.1 \pm 20.3$ & 0.534 \\
\hline & & $81.4 \pm 19.2$ & $81.2 \pm 23.0$ & 0.230 \\
\hline Pain & 19.3 & $\begin{array}{l}83.2 \pm 16.172 .4 \pm \\
28.572 .9 \pm 20.9\end{array}$ & $83.7 \pm 20.0$ & \multirow[t]{9}{*}{$\begin{array}{lll}0.533 & 0.578 & 0.153 \\
0.487 & 0.428 & 0.665\end{array}$} \\
\hline Planning & $\begin{array}{l}83.5 \pm \\
18.1\end{array}$ & \multirow{8}{*}{$\begin{array}{l}79.9 \pm 16.6 \\
77.3 \pm 20.2 \\
73.2 \pm 19.8\end{array}$} & $75.6 \pm 27.3$ & \\
\hline Intimate relationship & $742+$ & & $75.5 \pm 25.3$ & \\
\hline Burden to others & $27.7^{-1}$ & & $81.0 \pm 19.6$ & \\
\hline Emotional health & $74.2 \pm$ & & $76.6 \pm 27.5$ & \\
\hline Body image & & & $74.1 \pm 21.0$ & \\
\hline \multirow[t]{3}{*}{ Fatigue } & $18.1^{ \pm}$ & & & \\
\hline & $\begin{array}{l}77.0 \pm \\
24.1\end{array}$ & & & \\
\hline & $\begin{array}{l}73.7 \pm \\
20.4\end{array}$ & & & \\
\hline $\begin{array}{l}\text { Data are reported as } \\
\text { Activity Index 2000; } P \\
\text { Systemic Lupus Inter } \\
\text { Damage Index; HAQ- } \\
\text { Anxiety and Depressi }\end{array}$ & $\begin{array}{l}\text { ean } \pm \text { SD } \\
\text { A: physic } \\
\text { tional Co } \\
\text { Health A } \\
\text { Scale. }\end{array}$ & $\begin{array}{l}\text { number (\%). SLEDA } \\
\text { global assessmen } \\
\text { borating Clinics/An } \\
\text { essment Questionn }\end{array}$ & $\begin{array}{l}\text { : Systemic Lupus } \\
\text { DAS: Iupus low dis } \\
\text { can College of Rhe } \\
\text { Disability Index; ar }\end{array}$ & $\begin{array}{l}\text { hematosus Disease } \\
\text { se activity state; SDI: } \\
\text { atology (SLICC/ACR) } \\
\text { HADS: Hospital }\end{array}$ \\
\hline
\end{tabular}

\section{Ethical approval}

The study was approved by the Joint Chinese University of Hong Kong - New Territories East Cluster Clinical Research Ethics Committee (NTEC-2020-0254). This study was conducted according to the principles of the Declaration of Helsinki.

\section{Results}

From June to December 2020, 122 patients were randomized (TM: 60, SF: 62) and had at least 2 FUs (figure 1). At baseline, the mean age of the patients was $44.4 \pm 11.5$ years with a mean disease duration of 
$15.1 \pm 9.0$ years. Almost all patients had biopsy-proven LN class III, IV or V (88.5\%) and were on prednisolone (91.8\%). The majority of them (73.8\%) were on IS with the commonest being mycophenolate mofetil (47.5\%). While $63.9 \%$ of the patients were in LLDAS, none achieved disease remission. There were no baseline differences between the 2 groups except a higher PGA was observed in the TM group (mean $0.67 \pm 0.69$ vs $0.45 \pm 0.60, p=0.003$ ) (table 1 ).

The mean FU duration was $19.8 \pm 4.5$ weeks. When comparing the most recent visit, the mean waiting time from entering the clinic waiting room (virtual or real) to seeing a rheumatologist (virtual or in-person) was significantly shorter in the TM group $(22.5 \pm 28.6$ minutes vs $68.9 \pm 40.7$ minutes, $p<0.001)$ (figure $2 A)$. The mean overall patient satisfaction score was higher in the TM group (mean $2.19 \pm 0.61$ vs $1.89 \pm 0.78$, $\mathrm{p}=0.042$ ). The patients' satisfaction was similar in terms of the consultation alone (TM: $2.24 \pm 0.63$ vs SF: $2.05 \pm 0.80, p=0.251)$ as well as the explanation for medication usage and side effects (TM: $2.12 \pm 0.77$ vs SF: $2.09 \pm 0.67, p=0.596)$. The results of the post-consultation satisfaction questionnaire are shown in detail in figure 2B.

The number of visits was similar in the two groups (TM: $3.1 \pm 1.3$ vs SF: $3.0 \pm 1.2, p=0.981$ ). However, there was a trend suggesting that alternative mode of FU was being requested more frequently in the TM group than the SF group (TM: $12 / 60,20.0 \%$ and SF: $5 / 62,8.1 \% ; \mathrm{p}=0.057$ ). The main reasons in the TM group were perceived flares or new symptoms; while that for the SF group was fear of contracting SARS-CoV-2 (supplementary table 1). More patients in the TM group had hospitalization (15/60, 25.0\% vs 7/62, 11.3\%; $\mathrm{p}=0.049)$ within the study period. Logistic regression analysis revealed baseline PGA $(O R=1.15,95 \% \mathrm{Cl}$ 1.07-1.23, $p<0.001)$ rather than TM FU (OR 2.1, 95\% Cl 0.72-6.25, $p=0.176)$ was significantly associated with hospitalization. The number of hospitalizations related to SLE was numerically higher in the TM group (TM: $9 / 60,15.0 \%$ and SF: $4 / 62,6.5 \% ; p=0.151$ ) (supplementary table 2). None of the patients had COVID-19 and there was no mortality in either group during the study period.

The proportions of patients remained in LLDAS were similar in the 2 groups (TM: $75.0 \%$ vs SF: $74.2 \%$, $p=0.919$ ) (supplementary figure 2 ). The within group changes were not significant (TM: $p=0.064 ; S F$ : $p=0.804)$. Although the PGA was still higher in the TM group ( $0.52 \pm 0.49$ vs $0.36 \pm 0.40, p=0.025)$, there was no difference in the SLEDAl-2k between the 2 groups (TM: $3.58 \pm 1.91$ vs SF: $3.47 \pm 2.49, p=0.655$ ). The within-group and between-group changes in PGA over time were also not significant. At the last visit, there was no difference in the mean 24-hour proteinuria (TM: $0.52 \pm 0.63 \mathrm{~g}$ vs SF: $0.54 \pm 0.73 \mathrm{~g}, \mathrm{p}=0.894$ ) and prednisolone daily dose (TM: $6.04 \pm 5.09 \mathrm{mg}$ vs $\mathrm{SF}: 4.63 \pm 2.68 \mathrm{mg}, \mathrm{p}=0.073)$ between the two groups.

\section{Discussion}

As we define the new normal for ambulatory care in the COVID era, we need a new approach to provide care for our lupus nephritis patients, and TM has been the widely used alternative despite the lack of evidence. This is the first study comparing the patient satisfaction of TM versus standard in-person FU for lupus nephritis. We found that the overall patient satisfaction was higher in the TM group which could be partially driven by the much shorter pre-consultation waiting time. On the other hand, this might also 
be related to the intrinsic logistic convenience of TM, e.g. time saved from travelling. TM-based care appeared to be well received by patients with rheumatic diseases during the pandemic. In a Spanish study, it was found that for general soft tissue rheumatic diseases, the transfer of care activities to teleconferencing was met with a considerable degree of satisfaction for both the patients and the doctors (13). In another recent study on rheumatic patients with predominantly rheumatoid arthritis, $71.2 \%$ were satisfied with their virtual appointment (14).

The early results of our study showed that the proportions of patients remained in LLDAS were similar in both groups suggesting TM could be a valid option for lupus nephritis FU. A unique and fundamental element of disease activity assessment in lupus nephritis is the monitoring of proteinuria. This renders a virtual FU potentially more attractive for lupus nephritis than other rheumatic diseases where a physical examination is more essential. To this end, the development and validation of patient-reported-outcomes (PROs) in different rheumatic diseases are encouraged. Although our patients still needed to go to the clinic for blood and urine tests in both groups, the virtual FU and the fact that the prescribed medications could be collected by representatives of the patients in the near-by pharmacies minimized the risk of exposure to SARS-CoV-2. Due to the relatively low incidence of COVID-19 in Hong Kong during the study period, whether TM FU could reduce the infection risk could not be properly tested. The role of TM FU in other rheumatic diseases should be examined separately.

In this study, patients in the TM group had more hospitalizations and a higher tendency to change to SF than the reverse. These could off-set the conceived advantages of TM. Although the patients in the TM group had higher baseline PGA which could confound the results, there was no significant difference in the objective measures of lupus disease activity. In fact, the PGA in the TM group was persistently higher compared to the SF group which could be explained by the perceived higher disease activity when the patients were assessed virtually. The increased hospitalizations might reflect the lack of confidence of either patients or clinicians in accurately assessing the clinical condition, as we were not familiar with this mode of consultation. The clinical assessment of symptoms such as shortness of breath or weakness using TM is conceivably limited. It should also be pointed out that the major reasons for changing to in-person visit in the TM group were presumed disease flare or new-onset symptoms. It appeared that patients with higher physician assessed disease activity might not be optimally managed by TM alone, as higher baseline PGA was found be to be predictive of hospitalization. The elements contributing to the higher PGA in the TM group warrant further investigation as they could help identifying suitable candidates for TM care. A hybrid mode of FU with TM complemented by in-person visits when necessary might be helpful, and should also be investigated formally in clinical trials.

There are several limitations in this study. First, it was impossible to blind the patients and clinicians, the possibility of bias could not be eliminated. Secondly, only 6-month results of the study were presented. The long-term efficacy and cost-effectiveness results of TM in controlling the disease activity of patients with lupus nephritis will be available when the one-year FU has been completed. Moreover, a comprehensive analysis of use of TM should be based on a relevant conceptual framework, such as the Technology Acceptance Model, which would require in-depth assessment of the perceptions of the 
participants (both patients and healthcare professionals) (15). Lastly, our results should be interpreted in the context of the local COVID-19 transmission rate and anti-endemic measures implemented.

To conclude, we reported the early results of the first randomized controlled trial comparing TM and standard FU in patients with lupus nephritis. During the COVID-19 outbreak, TM FU resulted in better overall patient satisfaction when compared to standard care. However, it was associated with more hospitalizations. The preliminary data suggested TM was equally efficacious in maintaining disease control in patients with lupus nephritis in short-term. However, it might need to be supplemented by inperson visits, especially in patients with higher physician assessed disease activity.

\section{Declarations}

Acknowledgements We would like to express our gratitude to the University of Central Lancashire \& East Lancashire Hospitals NHS Trust for granting us permission to use the LupusQoL questionnaire.

Contributors All authors critically revised the manuscript for important intellectual content. Specific roles included: study design (HS, CCS, LST), data collection (HS, EC, ITC, SLL, TKL), data analysis (HS, EC, ITC, $S L L, T K L)$ and drafting of manuscript (HS, CCS, LST).

Data availability statement $D$ ata can be shared upon request.

Trial registration number NCT0436829

\section{References}

1. Severity of COVID-19 and survival in patients with rheumatic and inflammatory diseases: data from the French RMD COVID-19 cohort of 694 patients. Annals of the Rheumatic Diseases. 2020:annrheumdis-2020-218310.

2. Danza A, Ruiz-Irastorza G. Infection risk in systemic lupus erythematosus patients: susceptibility factors and preventive strategies. Lupus. 2013;22(12):1286-94.

3. Mikuls TR, Johnson SR, Fraenkel L, Arasaratnam RJ, Baden LR, Bermas BL, et al. American College of Rheumatology Guidance for the Management of Rheumatic Disease in Adult Patients During the COVID-19 Pandemic: Version 1. Arthritis Rheumatol. 2020;72(8):1241-51.

4. Landewé RB, Machado PM, Kroon F, Bijlsma HW, Burmester GR, Carmona L, et al. EULAR provisional recommendations for the management of rheumatic and musculoskeletal diseases in the context of SARS-CoV-2. Ann Rheum Dis. 2020;79(7):851-8.

5. McDougall JA, Ferucci ED, Glover J, Fraenkel L. Telerheumatology: A Systematic Review. Arthritis Care Res (Hoboken). 2017;69(10):1546-57.

6. de Thurah A, Stengaard-Pedersen K, Axelsen M, Fredberg U, Schougaard LMV, Hjollund NHI, et al. Tele-Health Followup Strategy for Tight Control of Disease Activity in Rheumatoid Arthritis: Results of a Randomized Controlled Trial. Arthritis Care Res (Hoboken). 2018;70(3):353-60. 
7. Cavagna L, Zanframundo G, Codullo V, Pisu MG, Caporali R, Montecucco C. Telemedicine in rheumatology: a reliable approach beyond the pandemic. Rheumatology (Oxford). 2021;60(1):36670.

8. So H, Szeto CC, Tam LS. Patient acceptance of using telemedicine for follow-up of lupus nephritis in the COVID-19 outbreak. Ann Rheum Dis. 2020.

9. Aringer M, Costenbader K, Daikh D, Brinks R, Mosca M, Ramsey-Goldman R, et al. 2019 European League Against Rheumatism/American College of Rheumatology Classification Criteria for Systemic Lupus Erythematosus. Arthritis Rheumatol. 2019;71(9):1400-12.

10. Ghazali WSW, Daud SMM, Mohammad N, Wong KK. Slicc damage index score in systemic lupus erythematosus patients and its associated factors. Medicine (Baltimore). 2018;97(42):e12787-e.

11. Gladman DD, Ibañez D, Urowitz MB. Systemic lupus erythematosus disease activity index 2000. J Rheumatol. 2002;29(2):288-91.

12. Fanouriakis A, Kostopoulou M, Alunno A, Aringer M, Bajema I, Boletis JN, et al. 2019 update of the EULAR recommendations for the management of systemic lupus erythematosus. Ann Rheum Dis. 2019;78(6):736-45.

13. Tornero-Molina J, Sánchez-Alonso F, Fernández-Prada M, Bris-Ochaita ML, Sifuentes-Giraldo A, VidalFuentes J. Tele-Rheumatology During the COVID-19 Pandemic. Reumatol Clin. 2020.

14. Howren A, Aviña-Zubieta JA, Rebić N, Dau H, Gastonguay L, Shojania K, et al. Virtual rheumatology appointments during the COVID-19 pandemic: an international survey of perspectives of patients with rheumatic diseases. Clinical Rheumatology. 2020;39(11):3191-3.

15. Davis FD, Bagozzi RP, Warshaw PR. User Acceptance of Computer Technology: A Comparison of Two Theoretical Models. Management Science. 1989;35(8):982-1003.

\section{Figures}




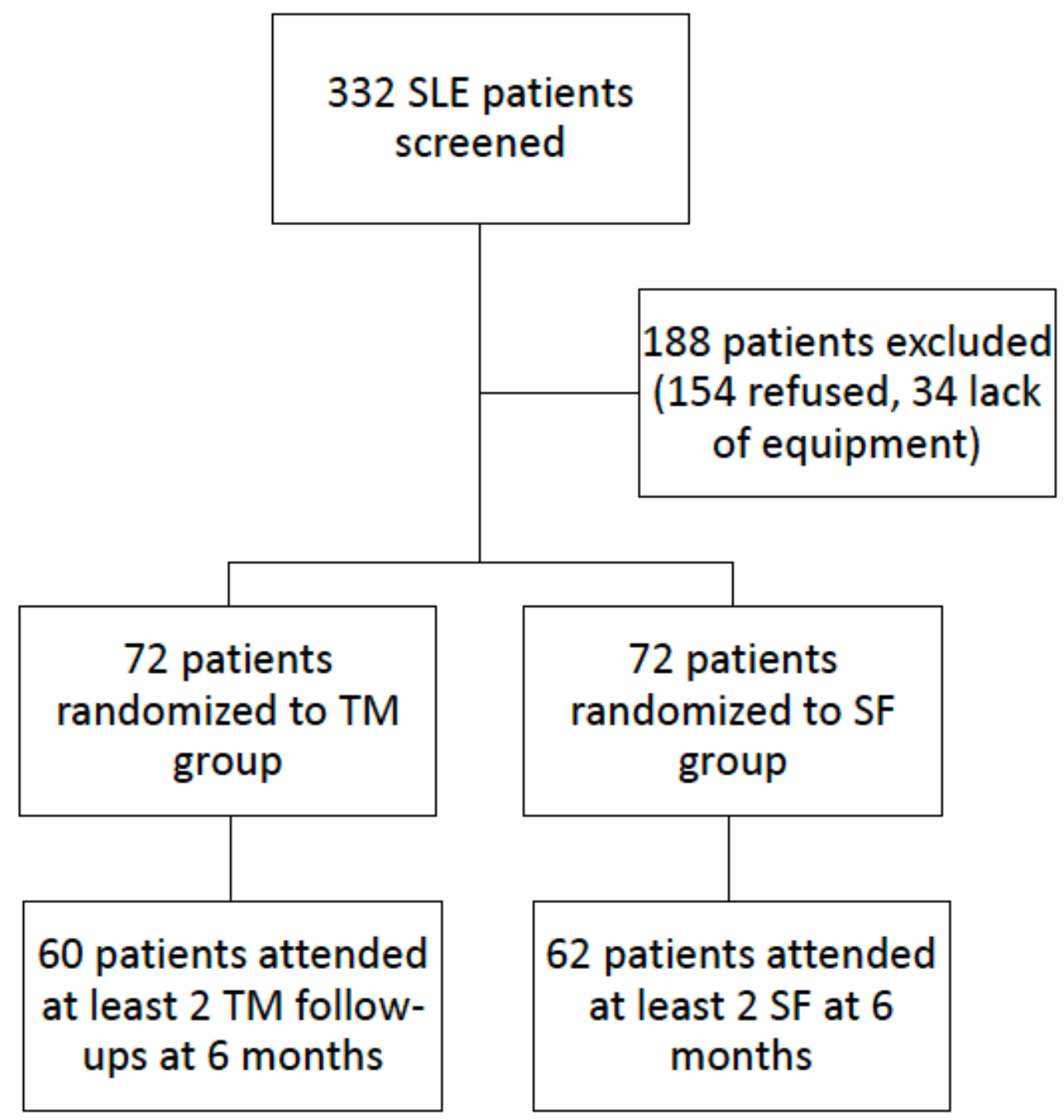

Figure 1

Trial profile. $\mathrm{TM}=$ Telemedicine, $\mathrm{SF}=$ Standard follow-up . 
A.

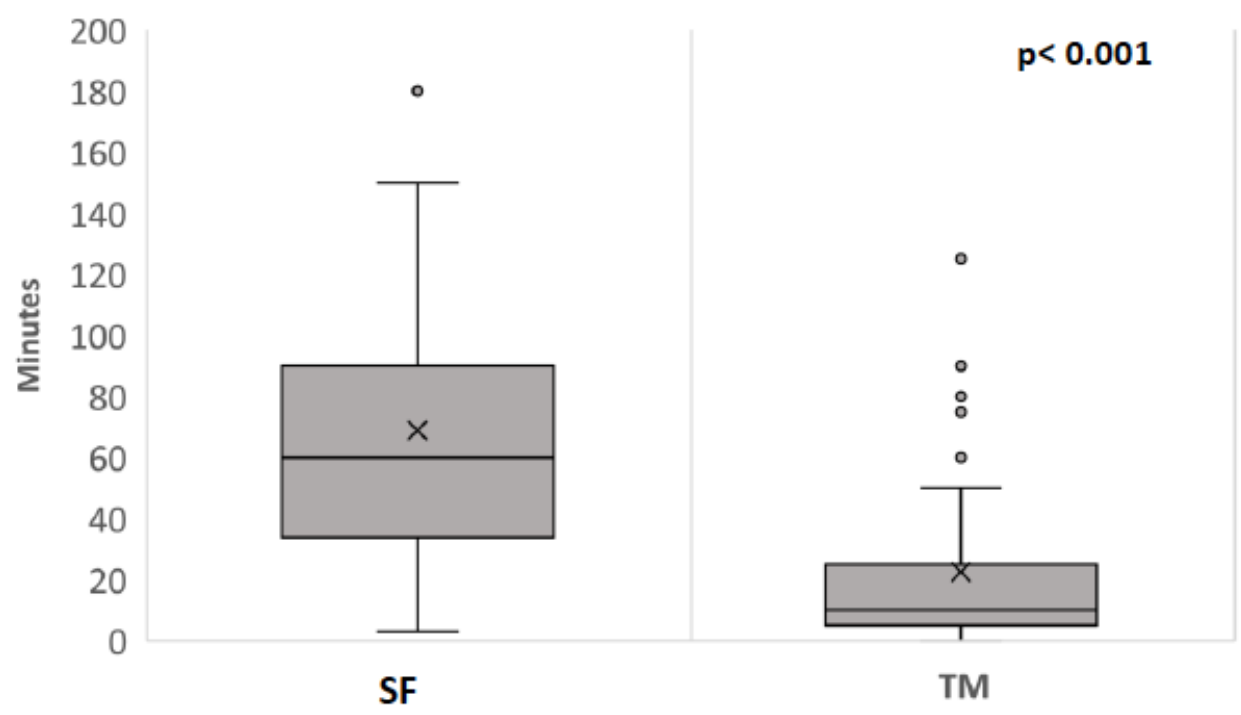

B.
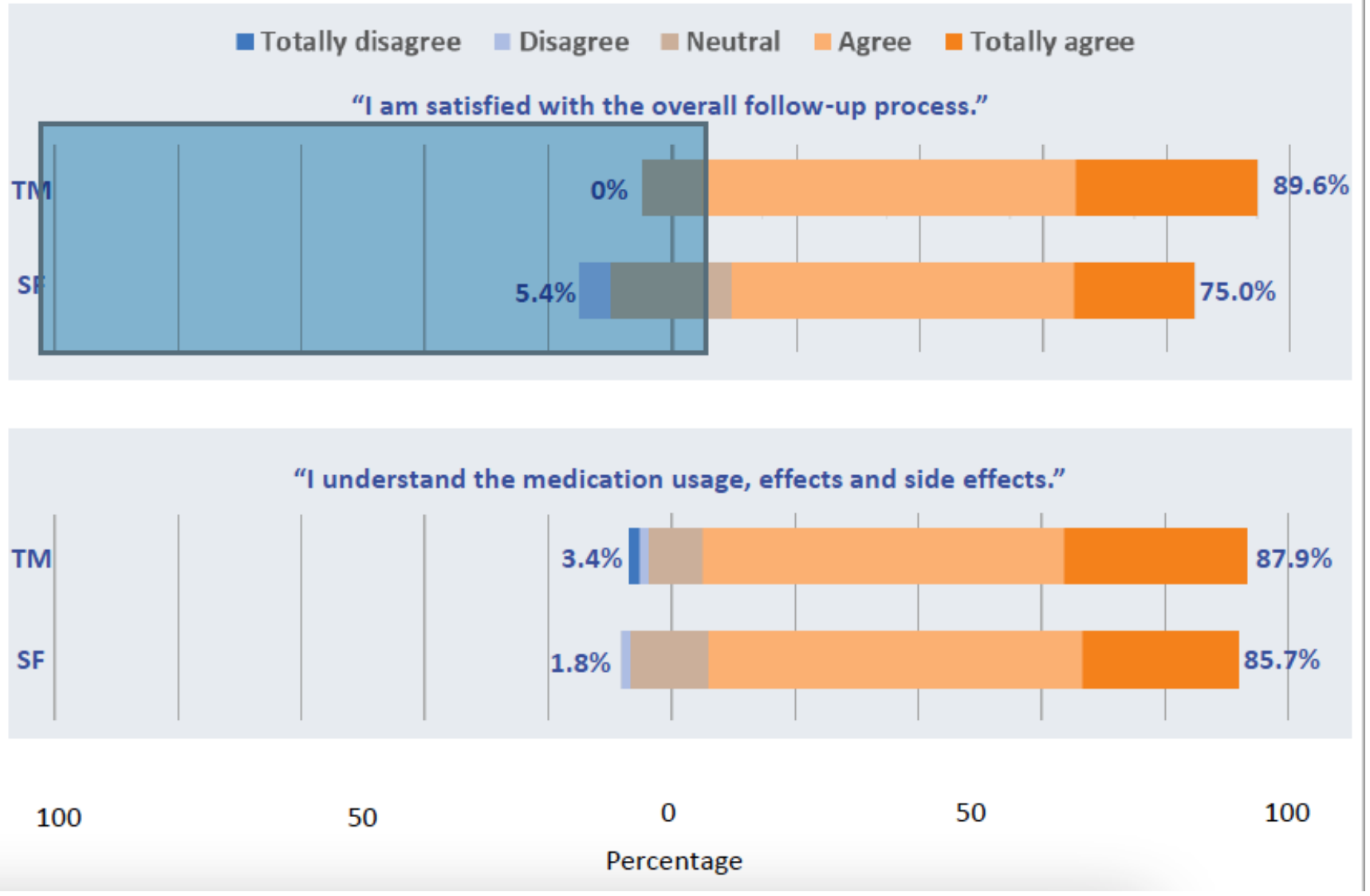

\section{Figure 2}

A. Mean waiting time between entering the clinic waiting room (virtual or real) and seeing a rheumatologist. $\mathrm{TM}=$ Telemedicine, $\mathrm{SF}=$ Standard follow-up. $\mathrm{B}$. The results of the post consultation satisfaction questionnaire. Response is shown as percentage with positive responses on the right. The neutral category was removed when calculating percentages. 


\section{Supplementary Files}

This is a list of supplementary files associated with this preprint. Click to download.

- Supplementarymaterial.docx 